\title{
Laboratory Measurement and Interpretation of the Changes of Physical Properties after Heat Treatment in Tight Porous Media
}

\author{
Yili Kang, Mingjun Chen, Lijun You, and Xiangchen Li \\ State Key Laboratory of Oil and Gas Reservoir Geology and Exploitation, Southwest Petroleum University, Chengdu 610500, China \\ Correspondence should be addressed to Mingjun Chen; chenmj1026@163.com
}

Received 25 September 2014; Accepted 30 December 2014

Academic Editor: Sachin Jangam

Copyright ( 2015 Yili Kang et al. This is an open access article distributed under the Creative Commons Attribution License, which permits unrestricted use, distribution, and reproduction in any medium, provided the original work is properly cited.

\begin{abstract}
Prevention of water blocking and optimization of multiscale flow channels will increase gas production of tight reservoirs. Physical properties of samples from representative tight gas reservoirs were measured before and after high temperature treatment. Results show that, with the increase of treatment temperature, mass decreases, acoustic transit time increases, and permeability and porosity increase. Permeability begins to increase dramatically if treatment temperature exceeds the threshold value of thermal fracturing, which is $600 \sim 700^{\circ} \mathrm{C}, 500 \sim 600^{\circ} \mathrm{C}, 300 \sim 500^{\circ} \mathrm{C}$, and $300 \sim 400^{\circ} \mathrm{C}$ for shale, mudstone, tight sandstone, and tight carbonate rock, respectively. Comprehensive analyses indicate that the mechanisms of heat treatment on tight porous media include evaporation and dehydration of water, change of mineral structure, generation of microfracture, and network connectivity. Meanwhile, field implementation is reviewed and prospected. Interpretations indicate that, according to the characteristics of multiscale mass transfer in tight gas formation, combining heat treatment with conventional stimulation methods can achieve the best stimulation result.
\end{abstract}

\section{Introduction}

Tight gas reservoirs, including shale gas, tight sandstone gas, and tight carbonate gas reservoirs, are playing an increasingly important role in the growth of natural gas reserves and energy supply. Gas production from tight gas reservoir is a process of multiscale mass transfer. In order to maximize the ability of gas production, it is necessary to optimize all the scales of mass transfer [1-4]. Single hydraulic fracturing mainly generates great-scale fractures based on preexisting fractures, but for tight gas reservoir, many of the reserves occur in small-scale pores. Meanwhile, in order to maximize fracture propagation, much more fracturing fluid is required to be pumped into formation. If the fluid system contains fresh water, the potential of clay swelling and migration would be extremely high. Considering that huge volume of liquid into formation is very difficult to flow back from the pores which have the ultrasmall volume and poor connectivity, various types of formation damage would be easily induced and the production cannot be satisfactory [5-7].
Therefore, effectiveness of conventional stimulation method is still not so good for tight gas reservoirs. A certain kind of stimulation method is urgent to be developed, and formation heat treatment, based on thermal property of rock, is developed as an innovative well stimulation technique, which is focused on prevention of water blocking and generation or propagation of small-scale fractures.

Formation heat treatment, which is recognized as a stateof-the-art technology for near-wellbore formation [8], might play a significant role in well stimulation. On the one hand, the water in pores would be removed perfectly, due to the evaporation or dehydration of water at high temperature. Therefore, formation damage like water blocking could be prevented, and permeability of rock is enhanced by removing water in gas flow channel [9-11]. On the other hand, induced fracture generates, preexisting fracture propagates, and finally various kinds of fractures connect to be network under the action of thermal stress at high temperature [1214]. As a result, the ability of mass transfer can be enhanced dramatically through formation heat treatment. Compared 
with conventional stimulation methods, like hydraulic fracturing and acid treatment, the advantages of formation heat treatment mainly consist in the following.

(1) It prevents water blocking by evaporation of blocked water and dehydration of clay structure [15].

(2) It enhances permeability and porosity in microscale uniformly. Meanwhile, it makes anisotropy of rock in mesoscale and macroscale under control.

(3) It accelerates desorption and diffusion of methane in matrix, especially for rocks rich in organic [16].

(4) Formation heat treatment does not need water source and it also does not contaminate groundwater. It is totally eco-friendly.

However, systematic studies on heat treatment are still rare and the application on stimulation of tight gas formation is urgent to understand. The previous studies on formation heat treatment are based on sandstone, and samples' permeability is relatively high $[8,9,15,17]$. Also, thermal cracking in rock, which has been studied a lot in nuclear waste storage, mining technique, HDR geothermal extraction, and stability analysis of constructions, is mostly based on granite that is not the natural gas reservoir [13, 18-21]. Therefore, the effect of high temperature on tight gas reservoirs, which is important in the development of petroleum industry, needs to be evaluated. Furthermore, the effect of heat treatment on different kinds of tight rocks also still needs to be distinguished. In this work, samples from the representative tight gas reservoirs were treated under high temperature in argon gas environment to simulate the in situ anoxic condition. Several lab experimental methods were comprehensively utilized to investigate the effect of heat treatment on physical properties of tight rocks. Then the essence of the changes of physical properties for tight rocks after heat treatment is analyzed comprehensively. Lastly, field implementation of heat treatment process is discussed.

\section{Experimental Sample and Procedure}

2.1. Samples' Description. Tight rock samples in this study are taken from three kinds of representative tight gas reservoirs. Shale samples are from the Longmaxi formation of Lower Silurian in Sichuan Basin, which is recognized as the most producible and profitable shale gas reservoir in China. Tight sandstone samples are from Upper Palaeozoic in Permian in Ordos Basin, which is the most giant tight sandstone gas reservoir in China. And the tight carbonate rock sample is from Feixianguan formation of Lower Triassic in northeast Sichuan Basin, which is the representative tight carbonate gas reservoir in China. Meanwhile, in order to investigate the influence of organic matter in thermal process, mudstone samples from Sichuan Basin are selected to be compared with shale samples. These reservoirs are typically characterized by various kinds of pore types, complicated pore structure, and strong heterogeneity. Porosity and permeability were measured by CMS-300 Core-Automatic Determination Instrument for permeability more than $0.01 \times 10^{-3} \mu \mathrm{m}^{2}$ and by LGPM700 with transient pulse decay method for permeability less than $0.01 \times 10^{-3} \mu \mathrm{m}^{2}$. Initial physical properties of these samples under conventional conditions (435 psi and $20^{\circ} \mathrm{C}$ ) are presented in Table 1.

2.2. Experimental Temperature Setting. X-ray diffraction (XRD) analyses of these samples show that clay mineral and quartz are the main minerals (Table 2), except that tight carbonate rock is mainly composed of dolomite. The clay minerals of samples mainly consist of illite, chlorite, kaolinite, and mixed-layer mineral of illite/smectite, except that shale does not contain kaolinite. Within a certain temperature range, structure of clay minerals would be destroyed. Besides clay minerals, thermal reactions can occur in other mineral constituents such as quartz and carbonate. Particularly the quartz, which has a volume expansion of $2.7 \%$ in $2 \sim 5$ seconds when temperature elevates to $573^{\circ} \mathrm{C}$ due to the $\alpha \rightarrow \beta$ inversion of quartz, has a dominant effect on the magnitude of thermal expansion $[19,22]$. Heats of reaction for several main minerals of samples are concluded in Table 3. According to the temperature range of heat reaction for minerals shown in Table 3, various temperature values, that is, 100, 200, 300, 400, $500,600,700$, and $800^{\circ} \mathrm{C}$, were specified as the temperature set-points to evaluate the effect of heat treatment on physical properties of tight rocks.

2.3. Experimental Equipment and Methods. In order to simulate the in situ anoxic condition, samples with corresponding irreducible water saturation were mounted in a tube furnace filled with argon gas. Mass of samples was measured before and after heat treatment by precision electronic balance in a controlled humidity oven at $20^{\circ} \mathrm{C}$ and $0 \% \mathrm{RH}$. Acoustic compressional wave ( $\mathrm{P}$-wave) and shear wave ( $\mathrm{S}$-wave) transit time were measured before and after heat treatment under conventional conditions ( $435 \mathrm{psi}$ and $20^{\circ} \mathrm{C}$ ) through SCMS$\mathrm{J}$ Acoustics-Resistivity Measurement Equipment, which is researched and developed independently by the State Key Laboratory of Oil and Gas Reservoir Geology and Exploitation of SWPU, and the frequency of ultrasonic wave is $170 \mathrm{kHz}$. Porosity and permeability were measured before and after heat treatment through CMS-300 for permeability more than $0.01 \times 10^{-3} \mu \mathrm{m}^{2}$ and through LGPM700 for permeability less than $0.01 \times 10^{-3} \mu \mathrm{m}^{2}$ under conventional conditions $\left(435 \mathrm{psi}\right.$ and $\left.20^{\circ} \mathrm{C}\right)$.

As is shown in Figure 1, the testing procedures are as follows.

(1) Measure one sample's mass, acoustic transit time, and porosity and permeability under the conditions shown above.

(2) Mount the sample in the tube furnace. Fully evacuate the sample at $62^{\circ} \mathrm{C}$ to ensure that air, including adsorbed gas, is excluded from the rock. Then break vacuum with argon gas until ambient pressure of sample returns to atmospheric pressure.

(3) Heat the sample to $100^{\circ} \mathrm{C}$ at a rate of $5^{\circ} \mathrm{C} / \mathrm{min}$, starting with atmospheric temperature $\left(20^{\circ} \mathrm{C}\right)$. When temperature in tube furnace is up to $100^{\circ} \mathrm{C}$, the testing temperature would be maintained for $2 \mathrm{~h}$ and then 
TABLE 1: Physical properties of samples without any heat treatment.

\begin{tabular}{|c|c|c|c|c|c|c|c|c|}
\hline Sample number & $\begin{array}{l}\text { Mass } \\
M_{0}, \mathrm{~g}\end{array}$ & $\begin{array}{l}\text { Length } \\
L_{0}, \mathrm{~cm}\end{array}$ & $\begin{array}{c}\text { Diameter } \\
D_{0}, \mathrm{~cm}\end{array}$ & $\begin{array}{c}\text { Porosity } \\
\Phi_{0}, \%\end{array}$ & $\begin{array}{c}\text { Permeability } \\
K_{0}, \\
10^{-3} \mathrm{um}^{2}\end{array}$ & $\begin{array}{l}\text { P-wave transit } \\
\text { time } \Delta T_{p}, \mu s / \mathrm{m}\end{array}$ & $\begin{array}{l}\text { S-wave transit } \\
\text { time } \Delta T_{s}, \mu \mathrm{s} / \mathrm{m}\end{array}$ & Lithology \\
\hline Shale1 & 63.3463 & 5.400 & 2.504 & 3.5 & 0.00780 & 221.2963 & 376.6667 & Shale \\
\hline Shale2 & 67.0235 & 7.396 & 2.482 & 4.6 & 0.0256 & 245.9438 & 408.8697 & Shale \\
\hline Shale3 & 42.9417 & 4.966 & 2.500 & 4.7 & 0.0947 & 247.8856 & 432.5413 & Shale \\
\hline Shale4 & 64.2955 & 6.040 & 2.500 & 3.8 & 0.0860 & 232.6159 & 390.0662 & Shale \\
\hline Sand1 & 41.0425 & 3.252 & 2.502 & 7.3 & 0.0167 & 287.3846 & 428.9231 & Sandstone \\
\hline Sand2 & 66.0089 & 5.268 & 2.478 & 4.6 & 0.0181 & 209.0288 & 383.9150 & Sandstone \\
\hline Sand3 & 59.5467 & 4.650 & 2.506 & 5.8 & 0.0465 & 274.0964 & 456.9707 & Sandstone \\
\hline Sand 4 & 60.1367 & 4.862 & 2.504 & 8.3 & 0.0571 & 328.9420 & 523.6723 & Sandstone \\
\hline Sand5 & 63.8542 & 5.308 & 2.488 & 8.8 & 0.0539 & 269.3178 & 421.0328 & Sandstone \\
\hline Carbonate & 55.8123 & 3.958 & 2.496 & 4.3 & 0.0135 & 160.2629 & 311.9312 & Carbonatite \\
\hline Mudl & 44.9856 & 4.210 & 2.482 & 5.3 & 0.0323 & 358.7732 & 482.4061 & Mudstone \\
\hline Mud2 & 46.8326 & 4.196 & 2.484 & 3.1 & 0.00711 & 322.8422 & 539.8188 & Mudstone \\
\hline Mud3 & 37.6457 & 3.392 & 2.488 & 2.3 & 0.00559 & 415.6342 & 688.4956 & Mudstone \\
\hline
\end{tabular}

TABLE 2: Quantitative analyses of minerals by XRD.

\begin{tabular}{|c|c|c|c|c|c|c|c|c|}
\hline \multirow{2}{*}{ Lithology } & \multicolumn{8}{|c|}{ Content of minerals, $\%$} \\
\hline & Clay mineral & Quartz & K-feldspar & Anorthose & Calcite & Dolomite & Siderite & Pyrite \\
\hline Shale & 39.96 & 41.15 & 3.12 & 5.12 & 2.91 & 4.11 & 0.00 & 3.63 \\
\hline Sandstone & 24.90 & 72.89 & 0.01 & 0.13 & 2.06 & 0.01 & 0.00 & 0.00 \\
\hline Carbonatite & 7.90 & 7.70 & 4.67 & 2.93 & 0.00 & 76.80 & 0.00 & 0.00 \\
\hline Mudstone & 56.52 & 11.14 & 0.00 & 7.04 & 25.30 & 0.00 & 0.00 & 0.00 \\
\hline
\end{tabular}

TABLE 3: Heats of reaction for several minerals [34, 35].

\begin{tabular}{lcl}
\hline Minerals & Temperature range, ${ }^{\circ} \mathrm{C}$ & Reaction after heat treatment \\
\hline Illite and clay mica & $125 \sim 250$ & Loss of hydroscopic water \\
Mg-chlorite & 650 & $14 \AA$ spacing is intensified \\
Fe-chlorite & 500 & $14 \AA$ spacing less intense, becoming broad and diffuse \\
Mixed-layer clays & $<600$ & Varies with amounts and types of minerals present \\
Kaolinite, well crystallized & $575 \sim 625$ & Replacement by amorphous metakaolin \\
Quartz & 573 & $\alpha \rightarrow \beta$ inversion \\
Ca-carbonate & $700-830$ & Decomposition \\
\hline
\end{tabular}

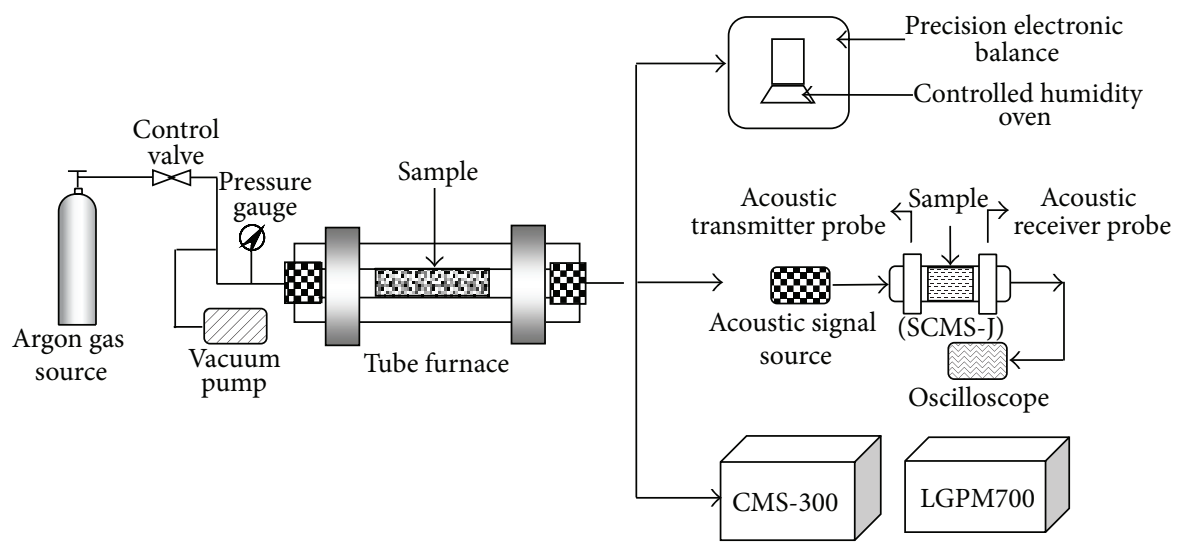

FIGURE 1: Schematic diagram of the experimental apparatus. 
decreases to the atmospheric temperature with a rate of $5^{\circ} \mathrm{C} / \mathrm{min}$.

(4) Measure the mass, acoustic transit time, and porosity and permeability through the same methods and conditions of the first procedure.

(5) Repeat the above steps with heating temperatures of $200,300,400,500,600,700$, and $800^{\circ} \mathrm{C}$, respectively. During the whole process of the heat treatment, the sample is always in argon gas atmosphere.

\section{Experimental Results}

3.1. Effect of Heat Treatment on Mass. Change of mass after heat treatment mainly reflects the loss of free water, adsorbed water, interlayer water, and constitution water. As is shown in Figure 2, mass of samples tends to decrease as treatment temperature increases. Meanwhile, the evident abrupt change of mass occurs at temperature lower than $200 \sim 300^{\circ} \mathrm{C}$ with temperature increasing. The mass is substantially unchanging if temperature is higher than that range.

Change of mass varies in different lithologies. Mudstone is the most affected. After heat treatment under $800^{\circ} \mathrm{C}$, its mass decreases as much as $2.38 \%$ on average compared with that before any heat treatment. Magnitude of mass decrease is $1.85 \%$ for shale, $0.55 \%$ for tight sandstone, and $0.10 \%$ for tight carbonate rock.

3.2. Effect of Heat Treatment on Acoustic Transit Time. Theoretically, acoustic transit time could increase if the porous media become less tight. Since evaporation or dehydration of water phase and thermal-induced fracturing are the most important mechanisms of heat treatment, change of the acoustic transit time in this work mainly reflects the change of pore structure. Experimental results show that transit time for both compressional wave ( $\mathrm{P}$-wave, $\Delta T_{p}$ ) and shear wave ( $\mathrm{S}$-wave, $\Delta T_{s}$ ) tends to increase as temperature increases (Figure 3), but the change is not very remarkable, as well as the change of porosity presented below. Comparing the acoustic transit time after heat treatment at $800^{\circ} \mathrm{C}$ with that before heat treatment, $\Delta T_{p}$ and $\Delta T_{s}$ increase as much as 1.19 times and 1.14 times for shale, 1.62 times and 1.55 times for tight sandstone, 1.10 times and 1.17 times for tight carbonate rock, and 1.13 times and 1.18 times for mudstone.

Since the responses of $\Delta T_{p}$ and $\Delta T_{s}$ to temperature are different, ratio of $\Delta T_{s}$ to $\Delta T_{p}\left(\Delta T_{s} / \Delta T_{p}\right)$ is necessary to be concerned with in order to comprehensively analyze the effect of heat treatment on physical properties, such as pore size and fracture propagation [23]. Outcome of the acoustic transit time measurement shows that change of $\Delta T_{s} / \Delta T_{p}$ does not have obvious regularity as the treatment temperature increases (Figure 4). Compared with $\Delta T_{s} / \Delta T_{p}$ without any heat treatment, the value after heat treatment at $800^{\circ} \mathrm{C}$ has a tendency of increase for shale and most of tight sandstone samples, but for tight carbonate rock and most of mudstone samples, it has a tendency of decrease.

3.3. Effect of Heat Treatment on Permeability and Porosity. In general, permeability is one of the physical properties

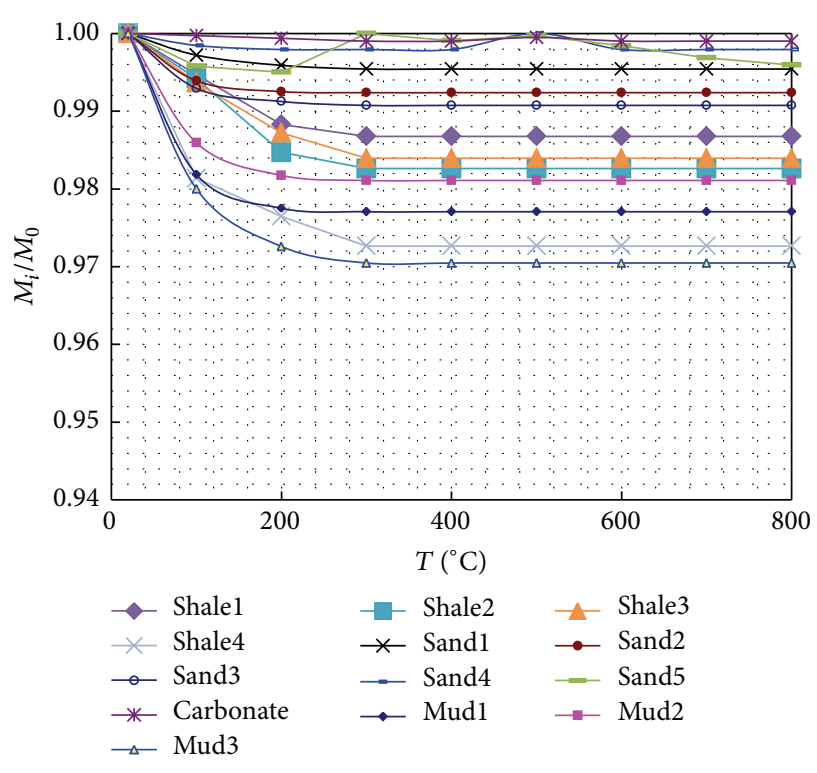

FIGURE 2: Normalized mass as a function of treatment temperature for all the samples.

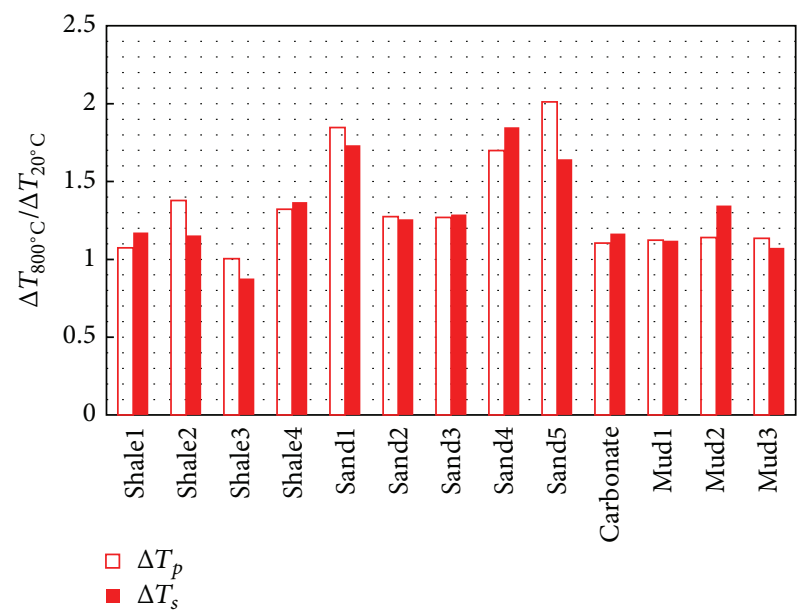

FIgUre 3: Ratio of acoustic transit time at $800^{\circ} \mathrm{C}$ to that at $20^{\circ} \mathrm{C}$ for all the samples.

that engineers are most concerned about. The permeability change caused by heat treatment is presented in Figure 5. Permeability tends to increase with the treatment temperature getting higher. What is more, permeability has an evident abrupt change within a certain temperature range. In detail, if temperature is lower than the threshold value, increase of the permeability is not so obvious, and if the temperature is higher than the threshold value, significant increase of the permeability occurs. Chen et al. (1999) recognized that percolation model could describe that change behavior perfectly [18].

Meanwhile, the variation of permeability by heat treatment is not the same for different lithologies. For the threshold temperature, shale is $600 \sim 700^{\circ} \mathrm{C}$, tight sandstone is $300 \sim$ $500^{\circ} \mathrm{C}$, tight carbonate rock is $300 \sim 400^{\circ} \mathrm{C}$, and mudstone is 


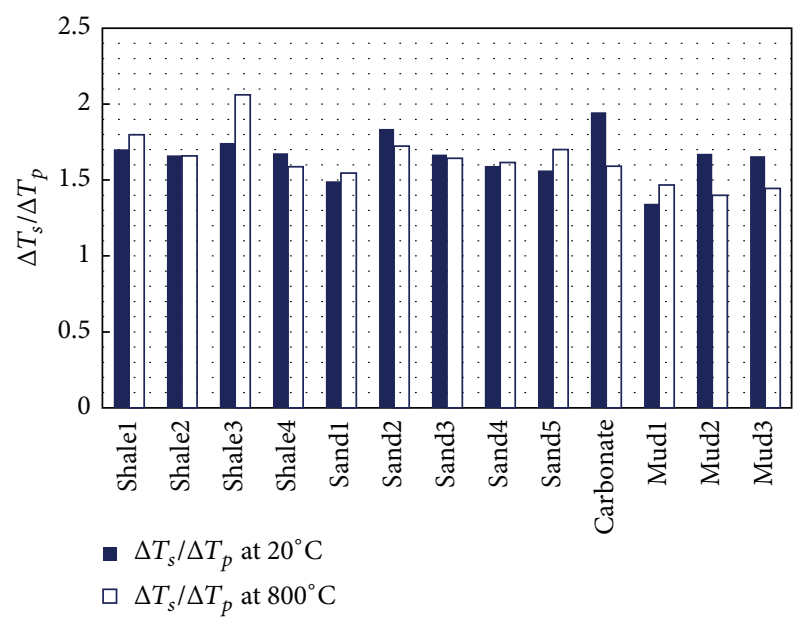

Figure 4: Ratio of $\Delta T_{s}$ to $\Delta T_{p}$ at $20^{\circ} \mathrm{C}$ and $800^{\circ} \mathrm{C}$ for all the samples.

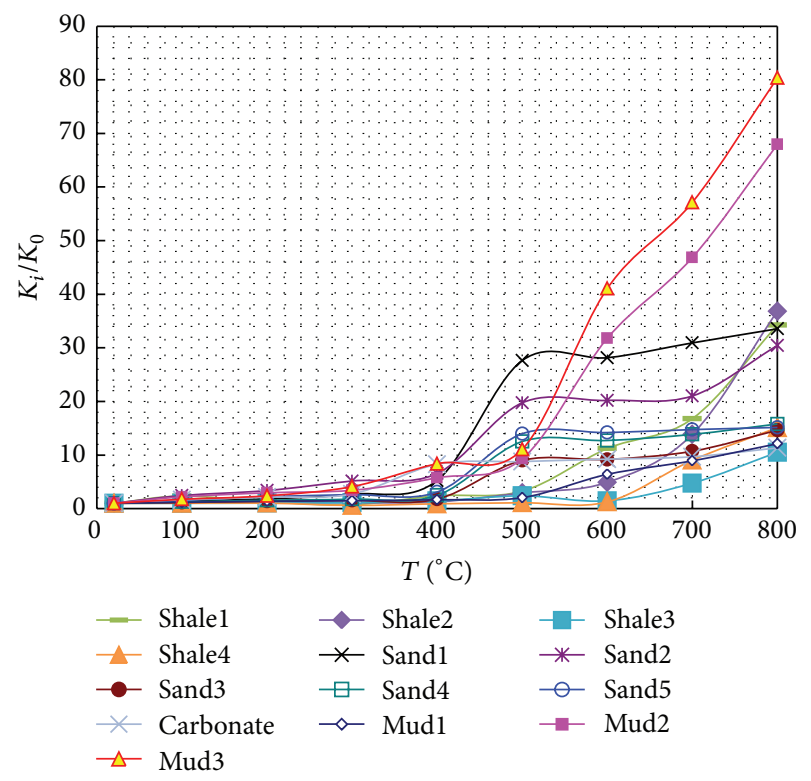

FIgURE 5: Normalized permeability as a function of treatment temperature for all the samples.

$500 \sim 600^{\circ} \mathrm{C}$. Compared with permeability without any heat treatment, the permeability of samples after $800^{\circ} \mathrm{C}$ treatment increases as much as 10.53 36.84 times (24.18 times on average) for shale, 14.63 33.55 times (21.92 times on average) for tight sandstone, 11.34 times for tight carbonate rock, and 12.11 80.36 times (53.47 times on average) for mudstone.

Effect of heat treatment on porosity is similar to that on permeability (Figure 6). It still has an abrupt increase within a specified temperature range, which is nearly the same as the change of permeability. In detail, as the treatment temperature elevates, increase of porosity is relatively slow if the temperature is lower than that range, but when temperature exceeds that range, the porosity has a relatively large increase. However, the increase of porosity is not as remarkable as that of permeability, and it also does not have a very evidently

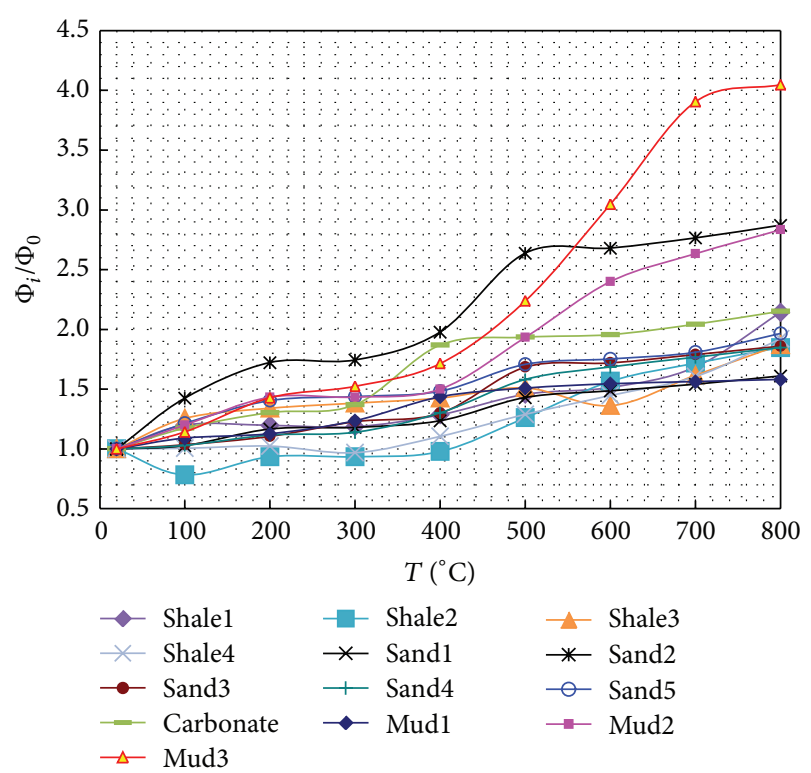

FIGURE 6: Normalized porosity as a function of treatment temperature for all the samples.

abrupt change within a range of threshold temperature. Meanwhile, the variation of porosity is not the same for different lithologies. Compared with porosity without any heat treatment, the porosity of samples after heat treatment at $800^{\circ} \mathrm{C}$ increases as much as $1.85 \sim 2.14$ times (1.95 times on average) for shale, 1.61 2.87 times (2.03 times on average) for tight sandstone, 2.15 times for tight carbonate rock, and 1.58 4.05 times (2.82 times on average) for mudstone.

\section{Discussions}

Tight gas reservoir has characteristics such as relatively small pore, richness in clay minerals or fragile minerals, complex flow paths, and serious anisotropy [24, 25]. Meanwhile, potential water blocking is quite easy to occur and difficult to prevent from the initial drilling and completion of wellbore to the depletion of reservoir during production. According to the experimental results shown above, physical properties of samples change remarkably after high temperature treatment. It is necessary to investigate mechanisms of the changes of physical properties.

4.1. Evaporation and Dehydration of Water Phase. Although the free water phase in pore can be easily excluded at about $100^{\circ} \mathrm{C}$, other water phases, that is, adsorbed water, interlayer water, and constitution water that exist within minerals, are not easily excluded [26]. Generally speaking, if temperature increases to $100 \sim 200^{\circ} \mathrm{C}$, adsorbed water and interlayer water can be excluded and constitution water in lattice can be excluded if the temperature is increased to $400 \sim 800^{\circ} \mathrm{C}$. The main reason for mass decrease in the experiment is the exclusion of adsorbed water and interlayer water. Evaporation and dehydration of water phase in pores expand the gas flow channel, and then permeability increases. 
Meanwhile, the dehydration of constitution water in clay minerals can make the newly generated minerals tighter and strengthen fragility of rock, which could be recognized as the function of consolidation and would accelerate the effectiveness of hydraulic fracturing [27, 28]. Besides, if the heating rate is high enough, such as microwave heating [1], instant evaporation of interlayer water would occur to make the mineral crystal fracture in the middle and separate from the edge of particle, which would generate microfracture and enhance the permeability evidently.

4.2. Mineral Phase Change and Decomposition at High Temperature. As is shown in Table 3, some physical or chemical reactions occur when the minerals absorb a certain amount of heat. The most consistent reaction is the inversion of quartz from the $\alpha \rightarrow \beta$ inversion at $573^{\circ} \mathrm{C}$. The amount of heat needed to complete this inversion is known to be $4.825 \mathrm{cal} / \mathrm{gm}$ [29]. The phase is fully reversible, so upon cooling, an equivalent amount of heat is liberated. The reason of highlighting the phase change of quartz is that quartz has a quick (2 5 seconds) volume expansion of $2.7 \%$ when quartz is heated to $573^{\circ} \mathrm{C}$, which can easily cause the strong thermalinduced stress. Therefore, when sample's temperature reaches $573^{\circ} \mathrm{C}$, it is prone to some degree of break.

4.3. Thermal-Induced Fracturing. Although thermal fracturing of rock has minor influence on bulk volume or density, it has a significant effect on pore structure, mainly reflected as generation and propagation of fracture. As rock is made up of different kinds of minerals, differences in thermal expansion of different minerals and differences in thermal expansion along different crystallographic axes of the same mineral can result in heterogeneity and anisotropy of thermal expansion, which generate thermal-induced stress [22]. Besides, if temperature gradient exists in rock, thermal expansion must be different in every part of rock even though thermal expansion coefficient of each mineral is the same, which could also generate thermal stress.

If thermal stress exceeds the ultimate tensile strength (tensile strength or compressive strength) at somewhere of the rock, microfracture would occur. Also, different heating rate and interval can cause different degree of thermal fracturing. Generally speaking, thermal fracturing tends to occur in the short axis direction of mineral particles [30]. Therefore, when temperature is relatively low, intercrystalline fracture is the main result of thermal fracturing, and as temperature increases, intracrystal fracture and transcrystalline fracture begin occurring [31].

According to the permeability measurement results, after $800^{\circ} \mathrm{C}$ treatment, permeability of samples increases as much as 24.18 times on average for shale, 21.92 times on average for tight sandstone, 11.34 times for tight carbonate rock, and 53.47 times on average for mudstone. In order to detect the mechanism of permeability enhancement caused by the generation of fracture, SEM (scanning electron microscopy) imaging was conducted before and after $800^{\circ} \mathrm{C}$ treatment, respectively. Meanwhile, to image the microstructure of shale more clearly, argon-ion milling was utilized to produce a much flatter surface. As is shown in Figure 7, various kinds of fractures were initiated or propagated after $800^{\circ} \mathrm{C}$ treatment. Meanwhile, SEM images show that thermal-induced fractures are generated in different scales depending on thermal expansion of different minerals. These fractures increase permeability remarkably.

4.4. Comprehensive Mechanisms of High Temperature Treatment. Comprehensive analyses of the above mechanisms indicate that essence of the changes of physical properties for tight rock after high temperature treatment is a set of multiscale processes involving evaporation and dehydration of water phase, change of mineral structure, and generation of fracture network. As is presented in Figure 8, the red arrow represents the process of thermal fracturing which produces microfractures from initiation and propagation to network connectivity.

According to the experimental results of permeability change, permeability has an evident abrupt change within a certain temperature range, which can be recognized as the range of threshold value based on percolation model. If the temperature is lower than the threshold value, effect of heat treatment is mainly reflected in evaporation or dehydration of water phase and minor generation of microfractures. Its main mechanism is to prevent water blocking in pores, but it cannot enhance permeability of tight rock essentially. Therefore, the main mechanism of permeability enhancement through heat treatment is the fracture network developed from initiation of microfracture and fracture propagation under the action of thermal stress when the treatment temperature is higher than the threshold value. Furthermore, kerogen in shale can strengthen the action of thermal stress compared to others without any organic materials. In detail, the kerogen would generate large amount of gas and oily product at certain high temperature, and when it is heated, these products would expand seriously, resulting in extending pressure [32]. If the value of extending pressure exceeds a certain critical value, the rock would develop more dramatic fracturing.

\section{Prospects on Field Testing}

The concept of formation heat treatment was first proposed by Jamaluddin et al. (1995) to solve formation damage induced by water blocking, which mainly aimed at relatively high permeability samples compared with the samples in this work [8]. For the application in industry, the earliest report was that of Albaugh (1954), on an oil well in California, which had an increase of $76 \%$ in production compared with that of pretreatment [33]. The other typical application in industry was that of Jamaluddin et al. (1999), on a field test that was carried out in a disused gas well, which made the permeability increase from $0.66 \times 10^{-3} \mu \mathrm{m}^{2}$ to $20 \times 10^{-3} \mu \mathrm{m}^{2}$ [17].

Since the high temperature has the risk of destroying casing/cement integrity, it needs to be considered in field application. Many excellent ideas have been presented, such as that of Jamaluddin et al. (1999) who designed and constructed an electrical down-hole heater by using highpressure nitrogen gas as the heat carrier [17]. What is more, several other ways to transport heat to objective formation 

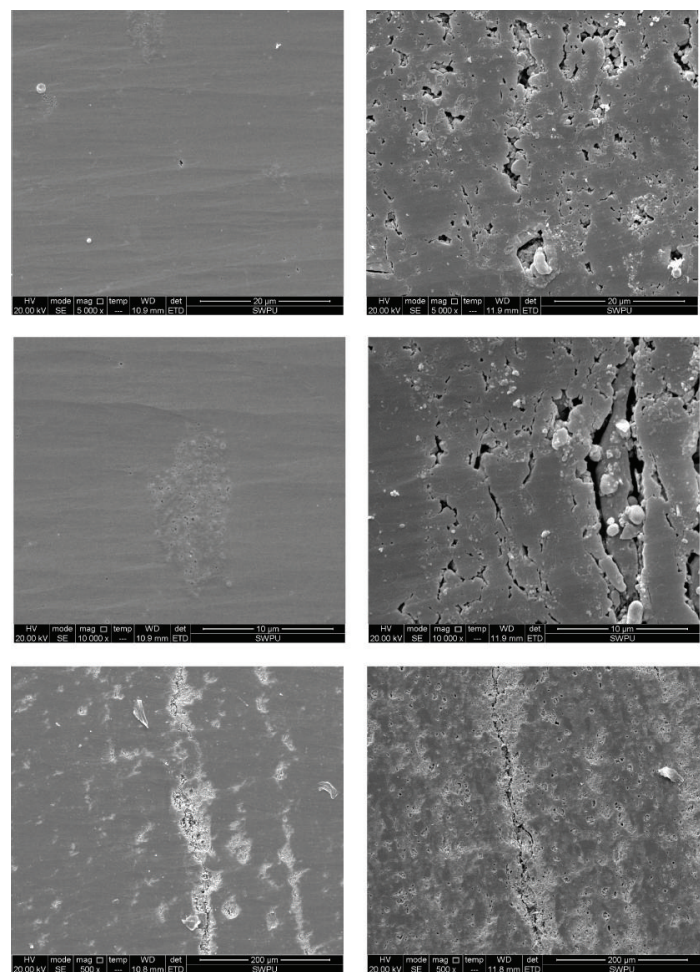

Before heat treatment

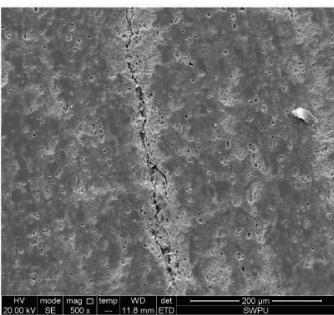

After heat treatment

(a) Shale
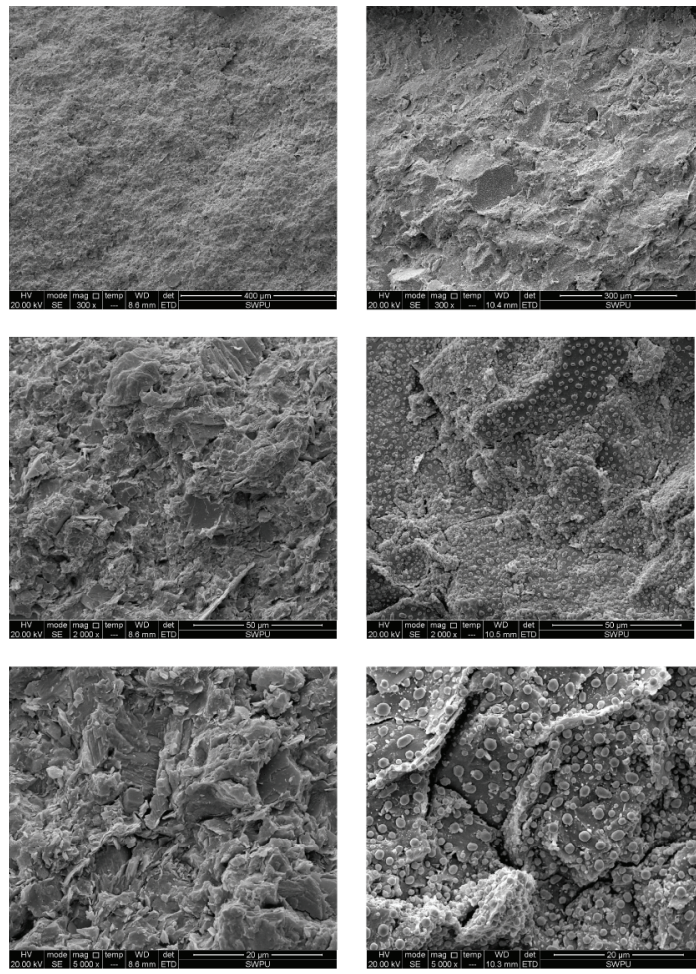

Before heat treatment
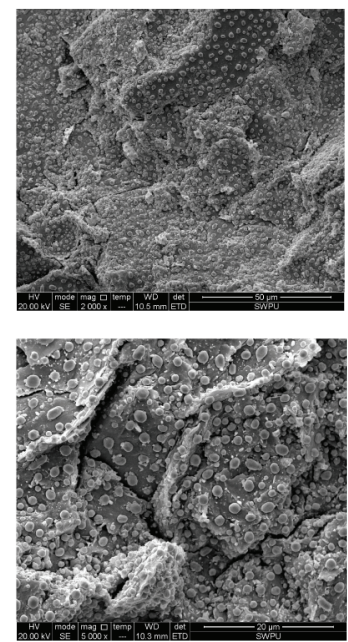

After heat treatment
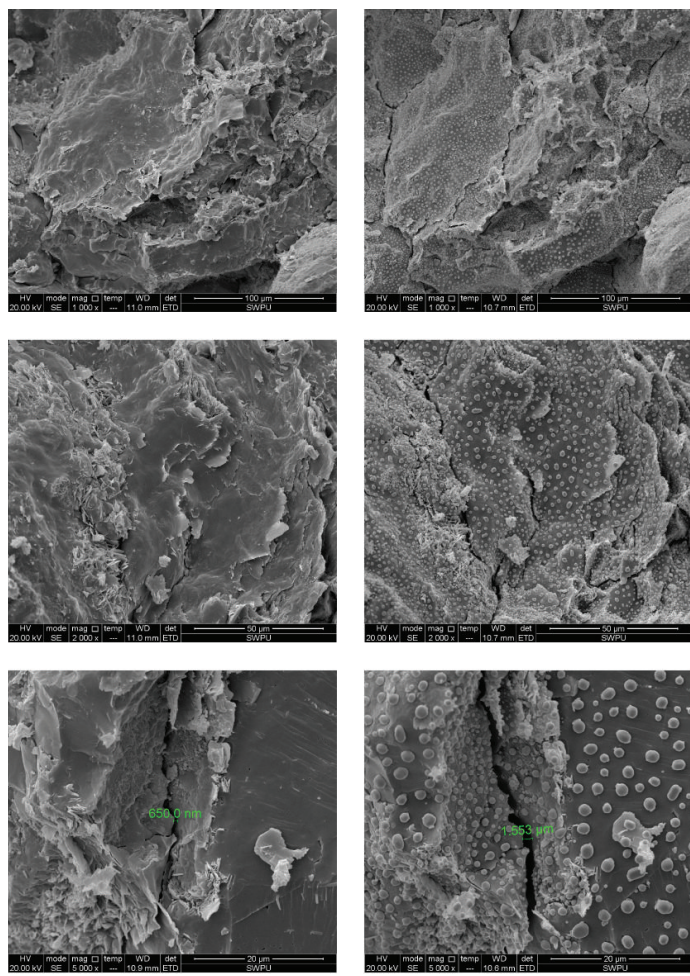

Before heat treatment

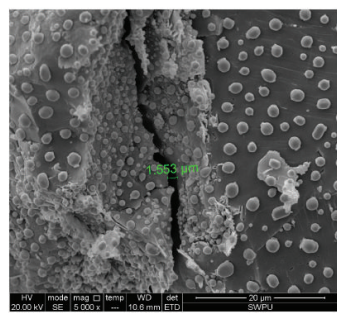

After heat treatment

(b) Tight sandstone
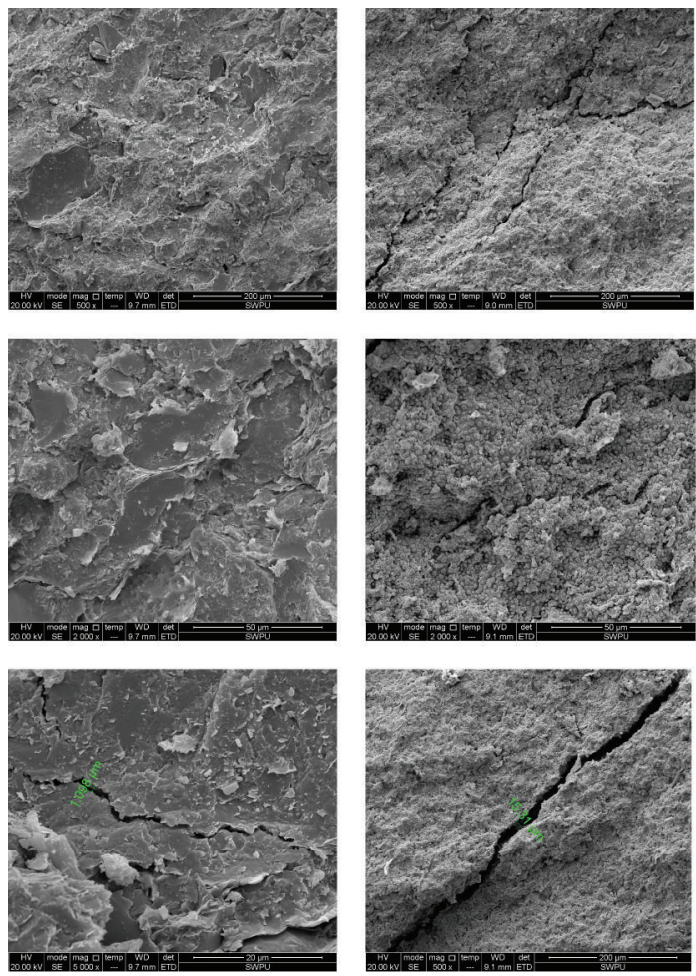

Before heat treatment

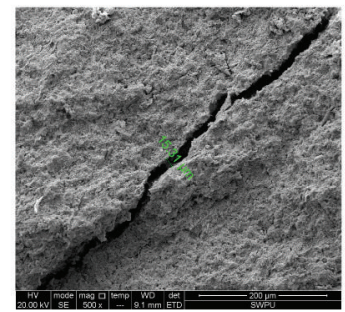

After heat treatment

(d) Mudstone

Figure 7: SEM of samples showing thermal-induced fractures after $800^{\circ} \mathrm{C}$ treatment. 
TABLE 4: Contribution of various stimulation methods on different scales of mass transfer.

\begin{tabular}{|c|c|c|c|c|c|}
\hline Scale & Formation heat treatment & Hydraulic fracturing & Gas-based fracturing & Acid treatment & Acid fracturing \\
\hline$S_{w}$ decrease & $\star \star \star \star ~$ & $\bullet$ & is & • & • \\
\hline Mineral reaction & $\star \star \star \star ~$ & is & is & $\star \star \star ~$ & $\star \star \star$ \\
\hline Microfracture generation & $\star \star \star \star ~$ & $\star \star$ & $\star \star$ & ts & $\star \star$ \\
\hline Meso/macrofracture generation & $\star \star$ & 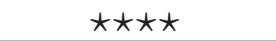 & $\star \star \star \star ~$ & ț & 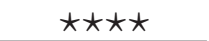 \\
\hline
\end{tabular}

$\star \star \star \star$ : predominant, $\star \star \star$ : secondary, $\star \star$ : weak, ヶ: ineffective, and $\bullet$ : harmful.

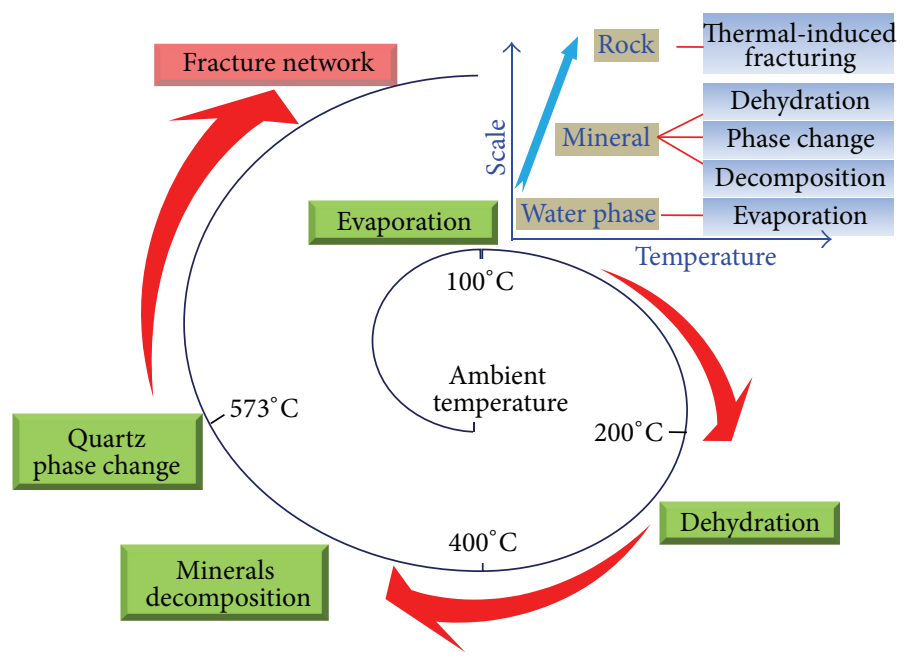

FIGURE 8: Mechanisms of heat treatment for tight rocks.

point, such as microwave [1] and high-power laser technology [20], are still very effective. These heating methods are all designed and constructed to enhance permeability most remarkably and avoid destroying the casing/cement integrity. Meanwhile, in order to heat the target depth accurately, coiled tubing system would be a very good choice. Also, the technology of coiled tubing is applicable in horizontal well, which can meet the requirement of staged stimulation in horizontal well.

Gas production of tight reservoirs is a typical multiscale mass transfer process, which is related to decrease of water saturation $\left(S_{w}\right)$, change of mineral structure, and generation and propagation of microfracture and meso/macrofracture. Table 4 summarizes the contribution of different stimulation methods, that is, formation heat treatment, hydraulic fracturing, gas-based fracturing, acid treatment, and acid fracturing, on the above four scales. Compared with other stimulation methods, the advantages of heat treatment are mainly reflected in the scale of reducing $S_{w}$ and generation of microfracture. The development of large amount of microfracture plays an important role in reducing fracturing pressure and generating fracture network for tight rock.

Generally speaking, gas production of tight reservoirs contains processes of desorption, diffusion, and slip flow. Therefore, only if the matrix pore, microfracture, and meso/macrofracture were suitably matched, could the highest production be achieved. Conventional stimulation method, such as hydraulic fracturing, mainly plays an important role in the propagation of meso/macrofracture and heat treatment method mainly works in the development of microfracture and prevention of water blocking. Therefore, combining heat treatment stimulation and other nonthermal stimulations can perfectly match all the scales of mass transport processes, resulting in the most effective stimulation.

\section{Conclusions}

In this work, physical properties after heat treatment for different lithologies are studied experimentally. Meanwhile, SEM imaging was implemented to detect microfracture development and other structural changes. Since formation heat treatment is a state-of-the-art technology for tight gas formation and the systematic studies are still in the infancy, results of this work are significant to deeply understand the advantage of heat treatment on gas production enhancement. Conclusions from this work are summarized as follows.

(1) Physical properties of tight rocks change significantly after specified temperature treatment. Generally speaking, shale and mudstone change more remarkably than tight sandstone and tight carbonate rock.

(2) The decrease of mass mainly occurs lower than 200 $300^{\circ} \mathrm{C}$. Acoustic transit time increases as temperature increases, except that the change of $\Delta T_{s} / \Delta T_{p}$ does not have obvious regularity. As temperature increases, permeability of shale, mudstone, tight sandstone, and tight carbonate rock increases remarkably at 
$600 \sim 700^{\circ} \mathrm{C}, 500 \sim 600^{\circ} \mathrm{C}, 300 \sim 500^{\circ} \mathrm{C}$, and $300 \sim 400^{\circ} \mathrm{C}$, respectively, which is the threshold temperature range of thermal fracturing for each lithology.

(3) Essence of the changes of physical properties after heat treatment for tight rock is a set of multiscale processes involving evaporation and dehydration of water phase, change of mineral structure, and generation of fracture network.

(4) Typical field applications are reviewed to confirm the feasibility of heat treatment in industry. Heating methods, such as high-pressure nitrogen and microwave, are presented to be effective in enhancing permeability remarkably and avoiding destroying the casing/cement integrity.

(5) Heat treatment can dramatically enhance permeability in the scale of matrix pore and microfracture. However, for the scale of meso/macrofracture, it is necessary to use conventional stimulation method. Therefore, integrating heat treatment with conventional stimulation might be the best choice.

\section{Conflict of Interests}

The authors declare that there is no conflict of interests regarding the publication of this paper.

\section{Acknowledgments}

This work was supported by the National Basic Research Program of China (2010CB226705), China Scholarship Fund, and Open Fund (PLN1117) of the State Key Laboratory of Oil and Gas Reservoir Geology and Exploitation (Southwest Petroleum University).

\section{References}

[1] G. Li, Y. F. Meng, and H. M. Tang, "Clean up water blocking in gas reservoirs by microwave heating: laboratory studies," in Proceedings of the International Oil \& Gas Conference and Exhibition in China, Paper SPE 101072, Beijing, China, December 2006.

[2] F. Javadpour, D. Fisher, and M. Unsworth, "Nanoscale gas flow in shale gas sediments," Journal of Canadian Petroleum Technology, vol. 46, no. 10, pp. 55-61, 2007.

[3] S. A. Najeeb, A. K. Mohammed, K. Hossein, and M. G. Ramona, "Physics and modeling of gas flow in shale reservoirs," in Proceedings of the Abu Dhabi International Petroleum Conference and Exhibition, Paper SPE 161893, pp. 2822-2836, Abu Dhabi, UAE, November 2012.

[4] J. Cai, E. Perfect, C.-L. Cheng, and X. Hu, "Generalized modeling of spontaneous imbibition based on hagen-poiseuille flow in tortuous capillaries with variably shaped apertures," Langmuir, vol. 30, no. 18, pp. 5142-5151, 2014.

[5] D. B. Bennion, F. B. Thomas, R. F. Bietz, and D. W. Bennion, "Water and hydrocarbon phase trapping in porous mediadiagnosis, prevention and treatment," Journal of Canadian Petroleum Technology, vol. 35, no. 10, pp. 29-36, 1996.

[6] L. J. You and Y. L. Kang, "Integrated evaluation of water phase trapping damage potential in tight gas reservoirs," in
Proceedings of the 8th European Formation Damage Conference, Paper SPE 122034, Scheveningen, The Netherlands, May 2009.

[7] J. Cai and S. Sun, "Fractal analysis of fracture increasing spontaneous imbibition in porous media with gas-saturated," International Journal of Modern Physics C, vol. 24, no. 8, Article ID 1350056, 2013.

[8] A. K. M. Jamaluddin, M. Vandamme, and B. K. Mann, "Formation heat treatment (FHT): a state-of-the-art technology for near-wellbore formation damage treatment," Paper SPE 95-67, presented at the Annual Technical Meeting, Calgary, Alberta, Canada, June 1995.

[9] A. K. M. Jamaluddin, D. B. Bennion, F. B. Thomas, and T. Y. Ma, "Application of heat treatment to enhance permeability in tight gas reservoirs," Journal of Canadian Petroleum Technology, vol. 39, no. 11, pp. 19-24, 2000.

[10] J. C. Cai and B. M. Yu, "A discussion of the effect of tortuosity on the capillary imbibition in porous media," Transport in Porous Media, vol. 89, no. 2, pp. 251-263, 2011.

[11] F. Meng, P. Zhong, Z. Li, X. Cui, and H. Zheng, "Surface structure and catalytic performance of Ni-Fe catalyst for lowtemperature CO hydrogenation," Journal of Chemistry, vol. 2014, Article ID 534842, 7 pages, 2014.

[12] C. Yong and C.-Y. Wang, "Thermally induced acoustic emission in westerly granite," Geophysical Research Letters, vol. 7, no. 12, pp. 1089-1092, 1980.

[13] Y. Zhao, Z. Wan, Y. Zhang et al., "Experimental study of related laws of rock thermal cracking and permeability," Chinese Journal of Rock Mechanics and Engineering, vol. 29, no. 10, pp. 1970-1976, 2010.

[14] H. Tian, T. Kempka, N. X. Xu, and M. Ziegler, "Physical properties of sandstones after high temperature treatment," Rock Mechanics and Rock Engineering, vol. 45, no. 6, pp. 11131117, 2012.

[15] A. K. M. Jamaluddin, L. M. Vandamme, T. W. Nazarko, and D. B. Bennion, "Heat treatment for clay-related near wellbore formation damage," Journal of Canadian Petroleum Technology, vol. 37, no. 1, pp. 56-63, 1998.

[16] C. R. Hartman, J. R. Ambrose, I. Y. Akkutlu, and C. R. Clarkson, "Shale gas-in-place calculations part II-multicomponent gas adsorption effects," in Proceedings of the North American Unconventional Gas Conference and Exhibition, Paper SPE 144097, The Woodlands, Tex, USA, June 2011.

[17] A. K. M. Jamaluddin, M. Hamelin, K. Harke, and H. McCaskill, "Field testing of the formation heat treatment process," Journal of Canadian Petroleum Technology, vol. 38, no. 3, pp. 38-45, 1999.

[18] Y. Chen, X. D. Wu, and F. Q. Zhang, "Experimental study of rock thermal cracking," Chinese Science Bulletin, vol. 44, no. 8, pp. 880-883, 1999.

[19] M. G. Keaney, C. Jones, P. Meredith, and S. Murrell, “Thermal damage and the evolution of crack connectivity and permeability in ultra-low permeability rocks," in Proceedings of the 6th North America Rock Mechanics Symposium, Paper ARMA 04537, Houston, Tex, USA, June 2004.

[20] R. M. Graves and E. T. Bailo, "Analysis of thermally altered rock properties using high-power laser technology," in Proceedings of the Canadian International Petroleum Conference, Calgary, Canada, June 2005.

[21] T. Mehmannavaz, M. Ismail, S. Radin Sumadi, M. A. Rafique Bhutta, M. Samadi, and S. M. Sajjadi, "Binary effect of fly ash and palm oil fuel ash on heat of hydration aerated concrete," The 
Scientific World Journal, vol. 2014, Article ID 461241, 6 pages, 2014.

[22] W. H. Somerton, Thermal Properties and Temperature-Related Behavior of Rock/Fluid Systems, Elsevier Science Publisher B.V., Amsterdam, The Netherlands, 1992.

[23] C. I. Killian, "The Vp/Vs ratio after 40 years: uses and abuses," in Proceedings of the SEG Annual Meeting, Paper SEG 2006-1183, New Orleans, La, USA, October 2006.

[24] W. C. James and P. B. Alan, "Petrophysics of low-permeability medina sandstone, Northwestern Pennsylvania, Appalachian Basin," The Log Analyst, vol. 39, no. 4, pp. 36-46, 1998.

[25] Y.-L. Kang and P.-Y. Luo, "Current status and prospect of key techniques for exploration and production of tight sandstone gas reservoirs in China," Petroleum Exploration and Development, vol. 34, no. 2, pp. 239-245, 2007.

[26] J. Mahadevan, M. M. Sharma, and Y. C. Yortsos, "Evaporative cleanup of water blocks in gas wells," SPE Journal, vol. 12, no. 2, pp. 209-216, 2007.

[27] R. H. Friedman, B. W. Suries, and D. E. Kleke, "Hightemperature sand consolidation," SPE Production Engineering, vol. 3, no. 2, pp. 167-168, 1988.

[28] M. C. Ross, E. Rangel, M. L. Castanier, S. P. Hara, and R. A. Kovscek, "A laboratory investigation of temperature-induced sand consolidation," SPE Journal, vol. 11, no. 2, pp. 206-215, 2006.

[29] K. K. Kelley and E. G. King, Contributions to the Data on Theoretical Metallurgy, U.S. Bureau of Mines Bulletin, Washington, DC, USA, 1960.

[30] J.-P. Zuo, H.-P. Xie, H.-W. Zhou, and S.-P. Peng, "Experimental research on thermal cracking of sandstone under different temperature," Chinese Journal of Geophysics (Acta Geophysica Sinica), vol. 50, no. 4, pp. 1150-1155, 2007.

[31] Y. Zhang, X. Zhang, and Y.-S. Zhao, "Process of sandstone thermal cracking," Chinese Journal of Geophysics, vol. 48, no. 3, pp. 656-659, 2005.

[32] Q.-R. Meng, Z.-Q. Kang, Y.-S. Zhao, and D. Yang, "Experiment of thermal cracking and crack initiation mechanism of oil shale," Journal of China University of Petroleum (Edition of Natural Science), vol. 34, no. 4, pp. 89-98, 2010.

[33] F. W. Albaugh, "Oil well production process," U.S. Patent 2,685,930, 1954.

[34] I. Barshad, "Temperature and heat of reaction calibration of the differential thermal apparatus," American Mineralogist, vol. 37, no. 8, pp. 667-694, 1952.

[35] D. Carroll, "Clay minerals: a guide to their x-ray identification," Special Paper of the Geological Society of America, vol. 126, pp. $1-80,1970$. 

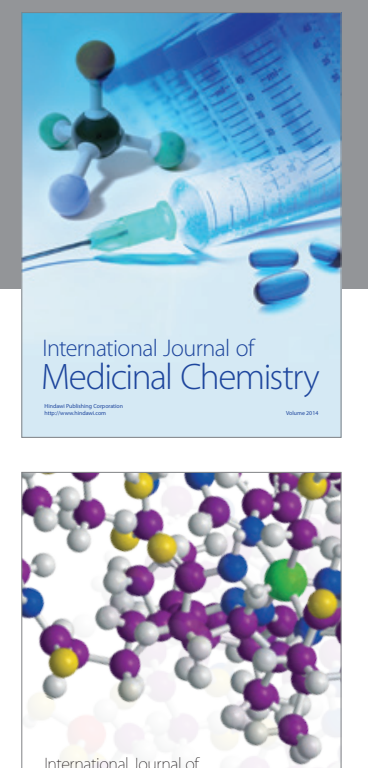

\section{Carbohydrate} Chemistry

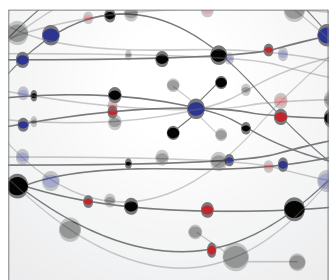

The Scientific World Journal
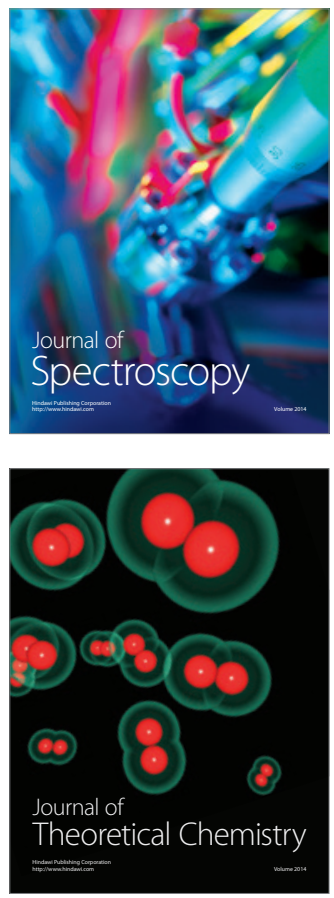
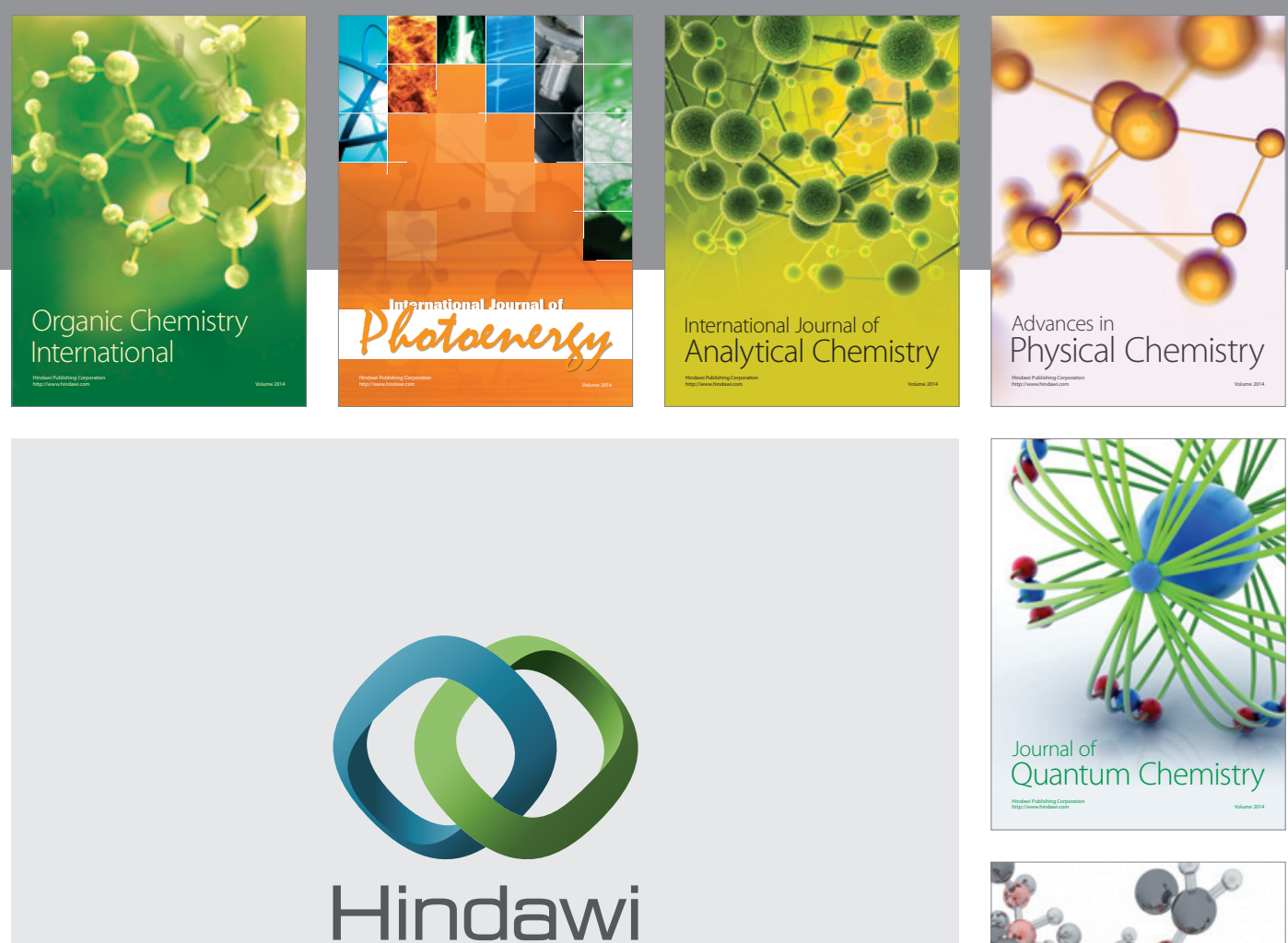

Submit your manuscripts at

http://www.hindawi.com

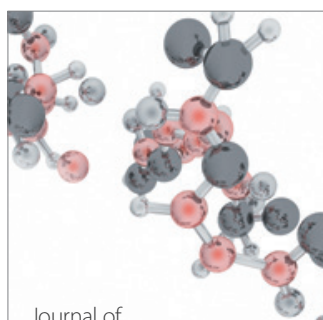

Analytical Methods

in Chemistry

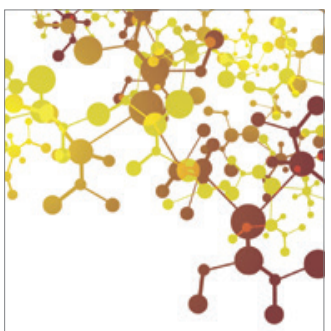

Journal of

Applied Chemistry

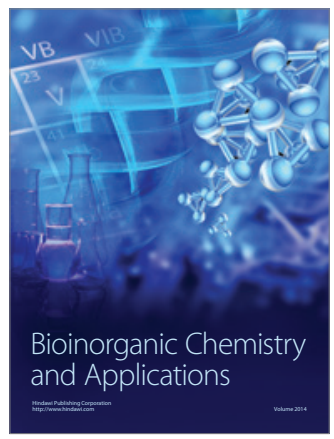

Inorganic Chemistry
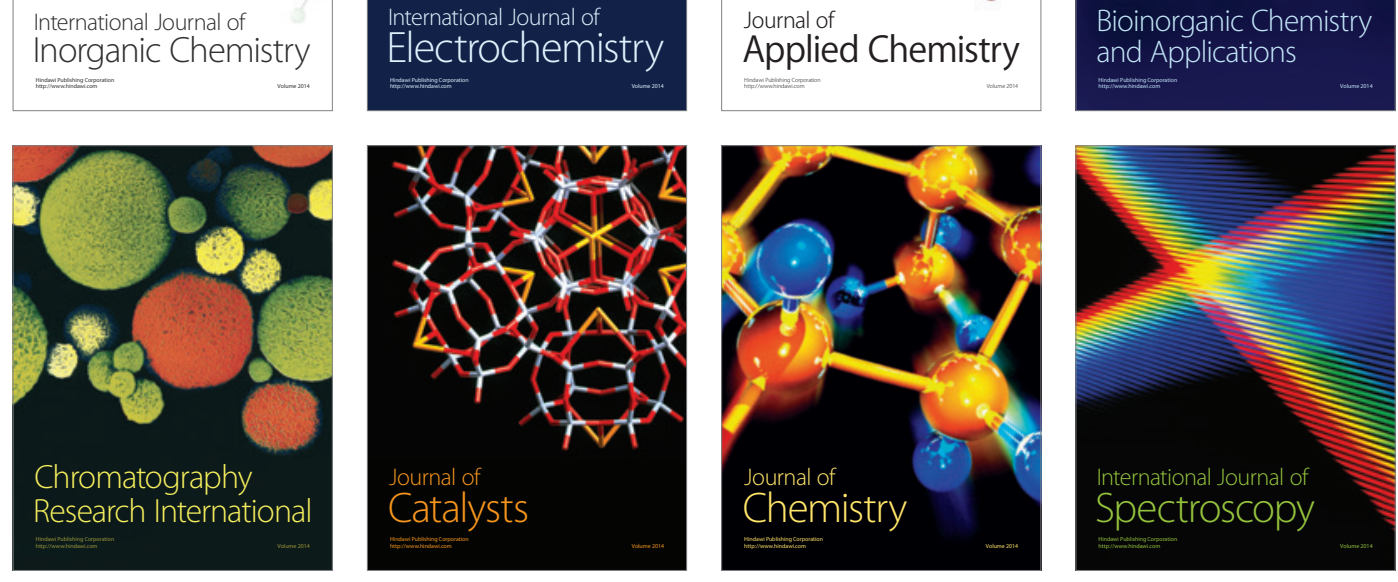